culture, Salisbury, for the broad programme of joint grassland research.

Dr. Keyston deals in some detail with the organisation of tobacco research under the suggested Rhodesia Nyasaland tobacco research association. $\mathrm{He}$ advocates also the establishment on a Central African footing of an agricultural machinery experimental station which might possibly also serve South and East Africa. Stress is laid on the importance of soil science; for a Central African soil laboratory the Agricultural Chemical Laboratory of the Department of Agriculture, Southern Rhodesia, provides the obvious nucleus. One central laboratory is required with good facilities for plant breeding, pathological and physiological research, including some accommodation for fundamental plant research, and specifically in association with the new herbarium to be constructed at Salisbury there should be provided good laboratory and nursery facilities for plant genetical, pathological and physiological investigations, including accommodation for visiting research workers. The same herbarium should be planned and constructed as a Central African herbarium, offering to all those territories scientific facilities and amenities comparable with those which the Royal Botanic Gardens at Kew offer to the United Kingdom. Forestry research is of especial importance. While substantially all sylvicultural research should be organised within the forestry departments of the three territories, most research on the utilization of timber is regarded as appropriate for a Central African construction experiment institute. Establishment on the copper belt of a chemical research laboratory to undertake work on wood chemistry, the discovery of new products derived from natural vegetation, agricultural crops and wastes and industrial chemical research pertinent to the establishment of Central African industries is suggested. Entomological research should be supervised by a Central African entomological research committee of the council, and in particular a Central African tsetse survey team, visualized as a self. contained mobile unit, is recommended.

For veterinary research in Southern and Northern Rhodesia, it is suggested that the veterinary departments at Salisbury and Mazabuka should each establish a research unit of not less than four officers, and that satisfactory arrangements should also be made with the Department of Agriculture, Pretoria, and the East African Veterinary Research Organisation, to include Rhodesian interests; but there is as yet no need for participation by Nyasaland in joint arrangements. Dr. Keyston strongly recommends that Southern Rhodesia should base its organisation for fisheries investigation on participation in the fisheries research project already prepared by the Northern Rhodesia and Nyasaland Governments. He suggests that the research council should stimulate more research on the fauna of Central Africa and that a fauna research committee should be set up, though the recruitment of biologists for such research is not recommended. Strongly supporting the conclusions relating to medical research in Southern Rhodesia of the report of the National Health Service Inquiry Commission (1946), Dr. Keyston recommends the institution, under the proposed RhodesiaNyasaland research council, of a medical research committee and a Central African medical research staff under an experienced specialist as director with headquarters, including specialist library, at Salis. bury. The maximum co-operation should be fostered between research and public health organisations. and arrangements made for interchange of staif annually between medical research authorities in the United Kingdom and the Union of South Africa and the new research centre. The programme of medical research should include disease surveys and nutritional surveys, while bilharziasis and malaria require special attention.

Sociological research directed towards assisting the administration is imperatively needed, and Dr. Keyston recommends the establishment of a Central African sociological research centre at Salisbury, whether or not this can be formed by re-siting and re-organising the Rhodes Livingstone Institute; and the programme of research should also comprise social experiment and fundamental sociological and anthropological studies. Besides all this, the report stresses the need for African personnel research, for which purpose a special research committee should be formed under the council, and the council should also be provided with statistical officers and with an operational research unit of at least six officers. To deal with buildings, roads and civil engineering works, a civil engineering research committee of the council is desirable as well as a co-ordinating committee for archæological and historical research and a museums board. On a rough estimate, Dr. Keyston puts the initial capital expenditure on the programme detailed in this third part of the report at $£ 135,850$, and the recurrent annual expenditure at $£ 266,000$; and a table is appended indicating the distribution of the expenditure between the different activities and the three Governments concerned. Scientific workers will note with appreciation the attention given throughout the report to conditions of service, which are clearly designed to prevent either staleness or the sense of isolation so detrimental to creative work.

\section{UNIVERSITY AND RESEARCH SECTION OF THE LIBRARY ASSOCIATION}
ANNUAL MEETING
$\mathrm{T}$ HE Uni ersity and Research Section of the Libran Association held its annual conference at Carlyle Hostel, Edinburgh, during September 15- 19. It was the first time that the Section had met in Scotland, and members took full advantage of the opportunity of visiting the many fine libraries and scholarly institutions in Edinburgh. The Section was welcomed by the principal of the University of Edinburgh, Sir Edward Appleton, at a reception in the Upper Library of the University. Sir Edward referred in his address to the spate of scientific literature confronting the research worker, and also urged the setting up of some central body to maintain a register of translations of papers originally written in unfamiliar languages.
Mr. R. Irwin, director of the University of London School of Librarianship, opened a discussion on training for university and research librarianship. He stressed the fact that the School course is a post- graduate course entirely, and urged university librarians to rely on the School for some, at least, of their trained recruits for permanent posts on library staffa. Mr. Irwin suggested that a starting salary of at least $£ 350-£ 400$ should be offered to the trained 
graduate taken on by university libraries, with reasonable prospects of promotion. He mentioned that very few science graduates were coming forward as candidates for librarian posts, and during the discussion it was pointed out that a science graduate is perhaps not likely to be attracted by a salary of $\mathfrak{\$ 3 5 0}$ when he can probably command more than that immediately upon taking his degree. Some scientific libraries seem willing to take graduates in other than scientific subjects.

The programme also included an address by Dr. H. W. Meikle, chairman of the Edinburgh University Library Committee, who gave a historical account of the libraries of Edinburgh; and a paper on the present condition and organisation of some of the libraries of northern Italy was read by Dr. W. Bonser, librarian of the University of Birmingham. Dr. Douglas Guthrie, lecturer on the history of medicine in the University of Edinburgh, spoke to the Medical Section on the evolution of medical studies in Scotland.

An important discussion on the future policy of the Section and its role within the Library Association was keenly followed by members present. Visits were paid to the National Library of Scotland, the Signet Library, the University Library, the City Library, and the Libraries of New College and the Royal Society of Edinburgh. The Medical Section inspected the University Medical Library and the Royal College of Physicians, while another party went to the Commonwealth Bureau of Animal Breeding and Genetics, and the small but pleasantly designed library of the Zoological Department of the University. This strenuous but interesting week-end was completed by a brief visit to Glasgow to inspect the University Library and the Royal Faculty of Physicians and Surgeons.

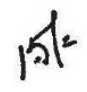

\section{MARINE BIOLOGY}

HE first number of Volume 28 of the Journal of the Marine Biological Association contains twelve plpers of interest to varied workers in this field. $N$.

Dr. N. Choss and Prof. J. Raymont describe two a thests of the results of fertilizing Loch Craiglin, an experiment which has been going on now for seven years. The records show considerable fluctuation, and even with small quantities of added fertilizer there is a disturbance in the natural balance of organisms, which may, over a period of years, affect the fauna detrimentally from the human point of view. Some of these results are unexpected. Thus, growth in size of the invertebrate population may be stimulated to such an extent that there is not sufficient small food available for young or for small-mouthed fishes such as the Pleuronectids. Prof. Raymont reports at least a hundred per cent increase in the bottom fauna; but does not find evidence of decrease in availability as fish food. The fish records, on the other hand, were disappointing, and Dr. Gross considers that unfavourable hydrographic conditions reduced the growth-rate, despite favourable feeding conditions. This led him to the conclusion that sexual maturity in flounders is correlated with size, not with age.

Five papers on the biology of marine organisms deal with Tubularia, copepods, Asterias, flagellates and sand eels. Those who have seen the handsome colonies of Tubularia larynx settled on rafts moored in the Firth of Clyde. in connexion with research on anti-fouling at the Millport Marine Biological Station, will welcome the interesting account by Messrs. Pyefinch and Downing of the biology of this species. The rapidity of settlement of the actinula larva after extrusion from the gonophore of the parent, and the production of actinulæ from the settled polyp, twenty-four days after settlement, account for the crowded colonies of this beautiful Colenterate.

Dr. Sheina Marshall continues her work on copepods by a study of seven species occurring in Loch Striven. All produce successive broods throughout the summer and, with the exception of Microcalanus pygmceus, show a seasonal vertical migration. The food of the copepods was studied, and it was found that Centropages and Temora are not dependent on diatoms entirely, but feed on small animals as well, while Microcalanus and Oithona subsist largely on flagellates. These feeding habits will affect the relative dis. tribution of the species at different times of the year.

The cannibalistic habits and tenacity of life of starfish, their rate of growth and the correlation between food and breeding rather than between size and breeding were worked out by $\mathrm{Mr}$. H. G. Vevers. It is not possible to determine the age of a starfish.

Dr. Mary Parke describes the specific characters and life-histories of the six minute flagellates used as food for oyster larvæ in the Port Erin oyster-rearing experiments, and her paper is illustrated by coloured plates.

Messrs. P. G. Corbin and Vidya Vati have worked out the post-larval stages of the three common sand eels, and have added a fourth from the Plymouth area, to which at present they give no name. Adult Gymnammodytes semisquamatus have been found in the region, but not, so far, the young.

A systematic study of the marine and brackish water rotifera of Plymouth has been made by $\mathbf{M r}$. E. D. Hollowday. There must be many biologists who have found rotifers in the plankton or among weed, and have been unable to identify them. Now there is no excuse, so far as these six species, illustrated by fine drawings, are concerned.

An ecological survey of the Exe Estuary is described by Mr. N. A. Holme. The erosion of Dawlish Warren is shown by aerial photographs taken in August 1945 and April 1946, and even in the short period of eight months a considerable portion of the sand-bank known as Warren Point has been washed away, causing redistribution of the sand, but with little effect on the physical conditions or the estuarine fauna. The species of plants and animals are listed relatively to the substratum of pure sand, muddy sand, and mud with Zostera. Mr. Holme concludes that soil drainage affects the fauna more than any other factor.

Mr. G. Chapman contributes a biophysical paper on the thixotropy of a marine soil, in relation to the burrowing speed of Arenicola marina $\mathrm{L}$. on the Whitstable flats (see Nature, December 4, 1948, p. 894). Dr. H. W. Harvey has estimated the amount of manganese available in sea-water off Plymouth at about $1.0 \mathrm{mgm}$. manganese $/ \mathrm{m}^{3}$, and off the Isle of Man at more than $2.0 \mathrm{mgm}$. m. ${ }^{3}$, the latter area being capable, therefore, of supporting a much richer summer population of flagellates. In fresh-waters the amount is still higher and may attain $40 \mathrm{mgm} . / \mathrm{m}$. in agricultural areas.

Finally, Dr. J. P. Harding describes how pro. bability paper can be used for the graphical analysis of polymodal frequency distributions, a useful contribution for statistical biologists. 